\title{
Hormonal mechanism of follicle deviation as indicated by major versus minor follicular waves during the transition into the anovulatory season in mares
}

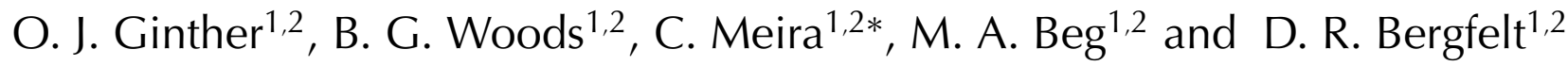 \\ ${ }^{1}$ Eutheria Foundation, Cross Plains, WI 53528, USA; and ${ }^{2}$ Department of Animal Health and Biomedical \\ Sciences, 1656 Linden Drive University of Wisconsin, Madison, WI 53706, USA
}

Follicle growth and circulating hormone concentrations were compared between an interovulatory interval and the first 60 days of the anovulatory season in pony mares. Daily observations were made from November of three groups: (i) ablation of follicles of $\geqslant 6 \mathrm{~mm}$ in diameter at day 10 after an ovulation that initiated an interovulatory interval, as determined retrospectively (ovulatory group, $n=8$ ), (ii) ablation at day 10 after the last ovulation of the year (anovulatory-10 group, $n=6$ ); and (iii) ablation at day 60 after the last ovulation of the year (anovulatory60 group, $n=6$ ). Follicular waves were defined as major (dominant follicle) and minor (no dominant follicle). The percentage of mares with major waves after ablation for the ovulatory, anovulatory-10 and anovulatory- 60 groups was 100,33 and $0 \%$, respectively, and the percentage with minor waves was 0,67 and $100 \%$, respectively. Minor waves were also detected in $83 \%$ of anovulatory mares between day 20 and day 60 . Growth of the largest follicle was similar for major waves and minor waves but only until the beginning of deviation in the major waves. FSH surges after ablation were similar for all groups and for surges detected during days 20-60. Concentrations of $\mathbf{L H}$ were greater in association with major waves than with minor waves. Both diameter of the largest follicle and LH concentrations for minor waves were greater after ablation at day $\mathbf{1 0}$ after the last ovulation of the year than after ablation at day 60 . The results of this study indicate that major follicular waves developed in some mares early in the anovulatory season and that minor waves developed throughout the first 2 months. Despite similarities in the wave-stimulating FSH surge, differences in follicle growth occurred and were attributable, on a temporal basis, to differences in LH concentrations. A minor wave developed into a major wave when the largest follicle reached a diameter characteristic of the beginning of deviation in the presence of an adequate LH stimulus for continued growth of a dominant follicle.

\section{Introduction}

A transition from ovulatory to anovulatory seasons occurs during the autumn in mares. In an initial study, plasma concentrations of $\mathrm{FSH}$ and numbers of follicles were not significantly different between a 31-day period after the penultimate ovulation and an equivalent period after the last ovulation (Snyder et al., 1979). It was concluded that the number of follicles and FSH concentration were not likely to be involved in the termination of the ovulatory season. In more recent studies, FSH concentrations apparently remained substantially unchanged until well into the anovulatory season (Nequin et al., 2000). In a study in which samples were collected every $6 \mathrm{~h}$, the mean daily $\mathrm{FSH}$ concentrations were qualitatively,

*On leave from the Department of Animal Reproduction and Veterinary Radiology, School of Veterinary Medicine and Animal Science-UNESP, Botucatu, SP, Brazil

Email: ojg@svm.vetmed.wisc.edu but not quantitatively similar between the last oestrous cycle and a comparable period after the last ovulation of the season (Irvine et al., 2000); the difference between peak and nadir values was reduced after the last ovulation. In contrast to $\mathrm{FSH}, \mathrm{LH}$ concentrations change considerably during the seasonal transition. An inadequate preovulatory surge of $\mathrm{LH}$ and final growth of the preovulatory follicle account for the absence of ovulation at the onset of the anovulatory season (Snyder et al., 1979). Similarly, in subsequent studies, failure to ovulate in the autumn was associated with an inadequate or absent LH surge (Irvine et al., 2000; Nequin et al., 2000).

Follicular waves, characterized by the simultaneous emergence and growth of a group of follicles, have been demonstrated in mares during the ovulatory season and pregnancy (Bergfelt and Ginther, 1992, 1993) and during the last part of the anovulatory season (Donadeu and Ginther, 2002, 2003). Both major waves (associated with a dominant follicle of $\geqslant 30 \mathrm{~mm}$ in diameter) and minor 
waves (no dominant follicle) have been found during these different reproductive states (Ginther and Bergfelt, 1992; Ginther, 1993). The hormone changes that account for the development of minor versus major waves have not been investigated.

In pony mares, the ovulatory follicle originates from a major follicular wave that is first detected by ultrasonography mid-way during an interovulatory interval of about 24 days (Gastal et al., 1997). The follicles develop in a common-growth phase for about 6 days and then deviate into a dominant follicle and subordinate follicles. Deviation begins when the largest follicle reaches a mean of about $22 \mathrm{~mm}$ in diameter. Deviation in diameter is recognized retrospectively from data profiles by a continuation in growth of the developing dominant follicle and a decrease or cessation in growth of the subordinate follicles.

The emergence of both minor and major waves is temporally associated with a surge in $\mathrm{FSH}$. This has been demonstrated both by normalizing $\mathrm{FSH}$ data to wave emergence and by normalizing follicle data to peak FSH concentrations. Despite a difference in follicular activity between the mid-anovulatory period and the transitional period before the first ovulation, FSH surges associated with follicular waves during these periods did not differ in either FSH concentrations or profile (Donadeu and Ginther, 2002, 2003). These results indicate that factors other than the characteristics of FSH surges account for the increased follicle responsiveness during the transition into the ovulatory season in the spring. Apparently, there have been no studies on the existence of the wave and deviation phenomena and associated FSH surges during the transition into the anovulatory season in the autumn.

The aim of the present study was to test the hypotheses that both major and minor follicular waves, defined by an emergence of a cohort of follicles, develop during the early portion of the anovulatory season and that the waves are temporally associated with changes in circulating concentrations of FSH. The nature of waves and surges was compared between an interovulatory interval and the first 60 days after the last ovulation (first 2 months of the anovulatory season). Emphasis was given to the temporal relationships among circulating concentrations of $\mathrm{FSH}, \mathrm{LH}$, oestradiol and total inhibin, and the hormone changes that may account for the occurrence of follicle deviation or the conversion of minor waves into major waves.

\section{Materials and Methods}

\section{Animals and treatments}

Non-lactating pony mares of mixed breeding, aged 9-16 years and 270-360 kg body weight, were kept under natural daylight in an open shelter in the Northern Hemisphere $\left(43^{\circ} \mathrm{N}\right)$. The mares had free access to grass hay, water and mineralized salt. The experiment started in November. Mares with ovarian follicles of $\geqslant 25 \mathrm{~mm}$ in diameter were monitored daily by transrectal ultrasonography to establish the day of ovulation. Retrospectively, the first ovulation that occurred in November was the beginning of an interovulatory interval in some mares (ovulatory mares) and was the last ovulation of the ovulatory season in other mares (anovulatory mares). At day 10 after the first ovulation in November, all follicles of $\geqslant 6 \mathrm{~mm}$ in diameter were ablated, using transvaginal ultrasonography as described by Gastal et al. (1997). This was performed to eliminate follicles from previous waves thereby maximizing the identity of follicles of the new wave. Beginning on day 4 after ablation, the six largest follicles of the new wave were measured each day by transrectal ultrasonography as described by Ginther (1995). A second ablation was performed in the anovulatory mares at day 60 after the last ovulation of the year and daily examinations continued for 10 days after ablation. Thus, follicle and hormone data were obtained for three groups: (i) ablation at day 10 after an ovulation that initiated an interovulatory interval (ovulatory group, $n=8$ ), (ii) ablation at day 10 after the last ovulation of the year (anovulatory-10 group; $n=6$ ), and (iii) ablation at day 60 after the last ovulation (anovulatory-60 group; $n=6)$; ablations at day 10 and at day 60 after the last ovulation were in the same mares.

\section{Blood sampling and hormone assays}

A blood sample from the jugular vein was collected into heparinized tubes each day from each mare for measurement of hormone concentrations. Plasma samples were collected during an interval extending from the pre-ablation ovulation up to a subsequent ovulation in the ovulatory mares and up to day 70 after the last ovulation of the year in anovulatory mares. The samples were immediately centrifuged at $500 \mathrm{~g}$ for $10 \mathrm{~min}$ and the plasma fraction was separated and stored at $-20^{\circ} \mathrm{C}$. Plasma concentrations of FSH and $\mathrm{LH}$ were measured by double antibody radioimmunoassays, as described for mares by Donadeu and Ginther (2002). Intra-assay and interassay coefficients of variation were 14.6 and $5.7 \%$ for $\mathrm{FSH}$ and 6.7 and $2.5 \%$ for $\mathrm{LH}$, respectively. Assay sensitivities were $1.7 \mathrm{ng} \mathrm{ml}^{-1}$ and $0.1 \mathrm{ng} \mathrm{ml}^{-1}$ for $\mathrm{FSH}$ and $\mathrm{LH}$, respectively.

Concentrations of total (immunoreactive) inhibin were measured by a double antibody radioimmunoassay kit (Institute of Reproduction and Development, Monash Medical Center, Clayton, Victoria), as described by Donadeu and Ginther (2001). The antibody recognizes dimeric forms of inhibin, as well as free $\alpha$-subunits (Roser et al., 1994). Nevertheless, total inhibin is a good indicator of FSH inhibitory activity in mares, as indicated by the consistent reciprocal relationship between circulating total inhibin and FSH concentrations during follicular wave development (Bergfelt et al., 2001; Donadeu and Ginther, 2001). Furthermore, during the last half of the anovulatory season and early ovulatory season, the profiles for circulating total inhibin (Donadeu 
and Ginther, 2002) were similar to those for inhibin A (Watson et al., 2002). The intra-assay coefficient of variation and sensitivity for total inhibin were $15.5 \%$ and $2.3 \mathrm{ng} \mathrm{ml}^{-1}$, respectively.

Plasma concentrations of oestradiol were measured by a double antibody radioimmunoassay kit (Double Antibody Estradiol, Diagnostic Products Corporation, Los Angeles, CA) after extracting the samples with ether, as described for mare samples by Gastal et al. (1999b). Intraassay and interassay coefficients of variation were 15.4 and $13.9 \%$, respectively, and the sensitivity was $0.3 \mathrm{pg}$ $\mathrm{ml}^{-1}$.

\section{Follicle and hormone endpoints}

The endpoints for the largest follicle (F1) and the second largest follicle (F2) refer to each day without consideration of day-to-day identity. The follicular wave after ablation was compared among the three groups, using the diameters of F1 and F2 for day 4 to day 12 after ablation in the ovulatory and anovulatory-10 groups; analysis was ended at day 12 because the first ovulation occurred at day 13. Day 4 to day 10 after ablation were also compared in order to include the anovulatory- 60 group. In addition, the days when F1 reached $12 \mathrm{~mm}$ and $20 \mathrm{~mm}$ in diameter were compared among the three groups. The waves after ablation were divided into major and minor waves. Major waves were defined as those in which maximum diameter of F1 was within the range of the maximum diameters of follicles that ovulated (28-40 mm). Minor waves were defined as those in which maximum diameter of F1 (22-25 mm) was smaller than the smallest ovulatory follicle and was within the range for F2 $(17-26 \mathrm{~mm})$ in the major waves. The day of the beginning of deviation in diameter was apparent in the major waves, using previously defined observational criteria (Gastal et al., 1997).

Follicular waves beginning and ending during days $10-50$ after ablation in the anovulatory-10 group were detected by an adaptation of a mathematical method described for mares by Ginther and Bergfelt (1992). The diameters of the 2 nd to 6th largest follicles (F2-F6) were analysed statistically within each mare. Data from F1 were excluded to minimize the variation within days. A significant increase in the mean diameter of F2-F6 was used to identify the beginning of a follicular wave. The day of emergence of a wave was defined by the beginning of the significant increase.

The concentrations of $\mathrm{FSH}$ after ablation were compared among the three groups for days 2-9 after ablation. Day 0 and day 1 were omitted because ablation appeared to have been performed during an FSH surge in five mares. Analysis was discontinued after day 9 because the surge after ablation ended by this day in each mare. Surges in daily FSH concentrations in the anovulatory mares beginning and ending during the interval between day 10 and day 50 after ablation within each mare were differentiated from variation

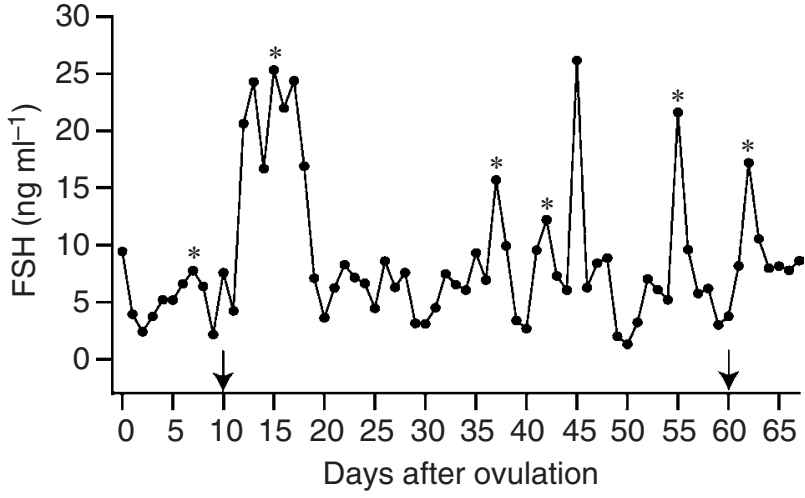

Fig. 1. Identified FSH surges after the last ovulation of the year in an individual anovulatory mare. Asterisks indicate the maximum value for an FSH surge and the arrows indicate days of ablation of follicles of $\geqslant 6 \mathrm{~mm}$ in diameter.

due to extraneous factors (variation in sampling or assaying technique), as described for mares by Fitzgerald et al. (1985). The coefficient of variation for FSH values composing the ascending and descending portions of the suspected surge or fluctuation had to be at least three times higher than the mean intra-assay coefficient of variation and had to include values from at least 2 days before and after the maximum value (Fig. 1). The highest value associated with an identified surge was defined as the peak. Concentrations of FSH in the anovulatory-10 group were compared between the surge after ablation and those identified between day 10 and day 50; the FSH peak was used as the reference point. The temporal relationships between follicles and identified surges during days 10-50 were examined by normalizing the mean diameter of F2-F6 to the peak of the surge and by normalizing FSH concentrations to the beginning of a defined wave.

Concentrations of $\mathrm{LH}$, oestradiol and total inhibin after ablation (days $0-10$ or days $0-13$ ) associated with the FSH surge after ablation were compared among the three groups (ovulatory, anovulatory-10 and anovulatory-60). Either a major or minor wave developed after ablation in each mare of the anovulatory-10 group, and the two types of wave were compared for concentrations of $\mathrm{LH}$, oestradiol and inhibin. In addition, minor waves after ablation were compared for these hormones between the anovulatory-10 mares and the anovulatory-60 mares.

\section{Statistical analyses}

Sequential data were analysed by the SAS MIXED procedure (SAS, 1995) using the animal as the random term to account for the autocorrelation among samples taken over time. For analysis of sequential data involving different groups, animal within group was used as the random term. Main effects of day, period and the interaction were determined. Differences among groups within a day and between discrete endpoints were examined by unpaired $t$ tests for comparing ovulatory 
and anovulatory-10 groups and by paired $t$ tests for anovulatory- 10 versus anovulatory- 60 groups. Significance was considered at $P<0.05$, whereas probabilities from $\geqslant 0.05$ to $<0.1$ were considered as approaching significance.

\section{Results}

During days 0-9 after ovulation (before ablation), the diameter of largest follicle and concentrations of $\mathrm{FSH}$ were not different between the ovulatory and anovulatory groups of mares (not shown). However, FSH surges encompassing the ascending and descending portions occurred on days 0-9 after ovulation (Fig. 1) in six of 14 mares, and an additional apparent surge overlapped the day of ablation in five mares. Follicle growth was not detected in association with these pre-ablation surges. A day effect $(P<0.001)$ for $\mathrm{LH}$ concentrations reflected high concentrations at day 0 and day 1 after ovulation, followed by a progressive decrease to day 4 . The group effect approached significance $(P<0.06)$ with higher $(P<0.02$ to $P<0.08)$ concentrations of $\mathrm{LH}$ in the ovulatory group on days $0,1,2$ and 3 after ovulation.

The number of days from ablation to the appearance of a follicle of $12 \mathrm{~mm}$ in diameter was not different among the ovulatory, anovulatory- 10 and anovulatory- 60 groups (Table 1). The day of appearance of a follicle of $20 \mathrm{~mm}$ in diameter was not different between the ovulatory and anovulatory-10 groups, but the maximum diameter of F1 was smaller in the anovulatory-10 group. A follicle of $20 \mathrm{~mm}$ in diameter was detected within 10 days in only one of six mares in the anovulatory-60 group compared with all mares in the other groups $(P<0.0001)$. The diameter of F1 during days 4-10 after ablation was not different between the ovulatory and anovulatory10 groups but was smaller in the anovulatory-60 group (group effect, $P<0.0001$; Fig. 2). The difference between the anovulatory- 60 group and the other two groups was significant $(P<0.02)$ on days $7,8,9$ and 10 , but not on days 4,5 and 6 . The diameter of $\mathrm{F} 1$ was smaller in the anovulatory-10 group than in the ovulatory group on day $11 \quad(P<0.02)$ and day $12 \quad(P<0.003)$, but not on earlier days (Fig. 2). Major waves as indicated by deviation between F1 and F2 occurred in all mares in the ovulatory group but in only two of six mares in the anovulatory-10 group (Table 1 ). In each of these two anovulatory mares, the dominant follicle reached a maximum diameter of $32 \mathrm{~mm}$. In the remaining four anovulatory mares, the waves were minor and $\mathrm{F} 1$ reached a maximum diameter of $22-25 \mathrm{~mm}$. However, the diameter of $\mathrm{F} 1$ in the four mares was greater $(P<0.05)$ at days 6-10 than for the diameter of F1 in the anovulatory60 group (not shown). The diameter profiles of F1 and F2 for the major and minor waves that followed ablation 10 days after ovulation are shown (Fig. 3).

The concentrations of circulating FSH for days 2-9 after ablation were different among days (Fig. 2;
Table 1. Mean \pm SEM characteristics of the new follicular wave after ablation of follicles 10 days after ovulation in mares that re-ovulated (ovulatory group) or entered the anovulatory season (anovulatory-10 group)

\begin{tabular}{lcc}
\hline Endpoint & $\begin{array}{c}\text { Ovulatory } \\
\text { group }\end{array}$ & $\begin{array}{c}\text { Anovulatory-10 } \\
\text { group }\end{array}$ \\
\hline Number of mares & 8 & 6 \\
Interovulatory interval (days) & $25.4 \pm 1.0$ & - \\
Number of days from ablation* & & \\
$\quad$ to 12 mm F1 & $4.4 \pm 0.6$ & $4.6 \pm 0.4$ \\
to 20 mm F1 & $7.8 \pm 0.5$ & $8.0 \pm 0.5$ \\
Maximum diameter (mm) & & \\
F1 & $37.0 \pm 1.5^{\mathrm{a}}$ & $27.5 \pm 1.7^{\mathrm{b}}$ \\
$\quad$ F2 & $19.4 \pm 1.7$ & $21.5 \pm 1.3$ \\
Deviation (major waves) & & \\
$\quad$ Number of mares & 8 of $8^{\mathrm{a}}$ & 2 of $6^{\mathrm{b}}$ \\
Diameter F1 at beginning & $23.3 \pm 1.2$ & $19.5 \pm 0.5$ \\
\hline
\end{tabular}

*F1 and F2 are the largest and second largest follicles of the follicular wave. There was no difference among groups in the number of days before a $12 \mathrm{~mm}$ F1 was obtained, including the anovulatory- 60 group ( $5.4 \pm 0.3$ days), but only one of six mares in the anovulatory- 60 group developed a $20 \mathrm{~mm}$ F1.

${ }^{\mathrm{a}, \mathrm{b}}$ Values with different superscripts within a row are significantly different $(P<0.05)$.

$P<0.0001)$. Peak mean concentrations of FSH averaged over the three groups occurred at day 5. An increase in $\mathrm{FSH}$ concentration $(P<0.05)$ started between day 2 and day 3 and a decrease $(P<0.05)$ occurred between the peak and day 7 . Concentrations of FSH were not different among the three groups and did not show a day-by-group interaction. Concentrations of $\mathrm{LH}$ for days 2-10 were different among groups (group effect; $P<0.003)$; $\mathrm{LH}$ concentrations first increased $(P<0.05)$ between day 3 and day 5 in the ovulatory group and between day 2 and day 3 in the anovulatory-10 group and remained low in the anovulatory-60 group (Fig. 2). A decrease $(P<0.05)$ began in the anovulatory-10 group at day 6 , so that at days 8,9 and 10 concentrations were lower $(P<0.05)$ than in the ovulatory group. The $\mathrm{LH}$ concentrations of mares with major waves were higher $(P<0.02)$ on each of day 6 and day 7 than those for the mares with minor waves (Fig. 4). In addition, concentrations were greater $(P<0.05)$ on days $3-6$ in the four anovulatory-10 mares with a minor wave than for the anovulatory-60 group (not shown). Concentrations of $\mathrm{LH}$ and statistical results normalized to observed deviation are shown (Fig. 5).

A total of five minor follicular waves and no major waves were detected during days 10-50 in the anovulatory-10 group. The minor waves began on days $30,32,38,40$ and 42 in five separate mares. The $\mathrm{FSH}$ concentrations normalized to the beginning of the waves were not significant. However, an increase beginning at day 5 before emergence of the waves $(P<0.1)$ and a decrease beginning on the day of emergence of 

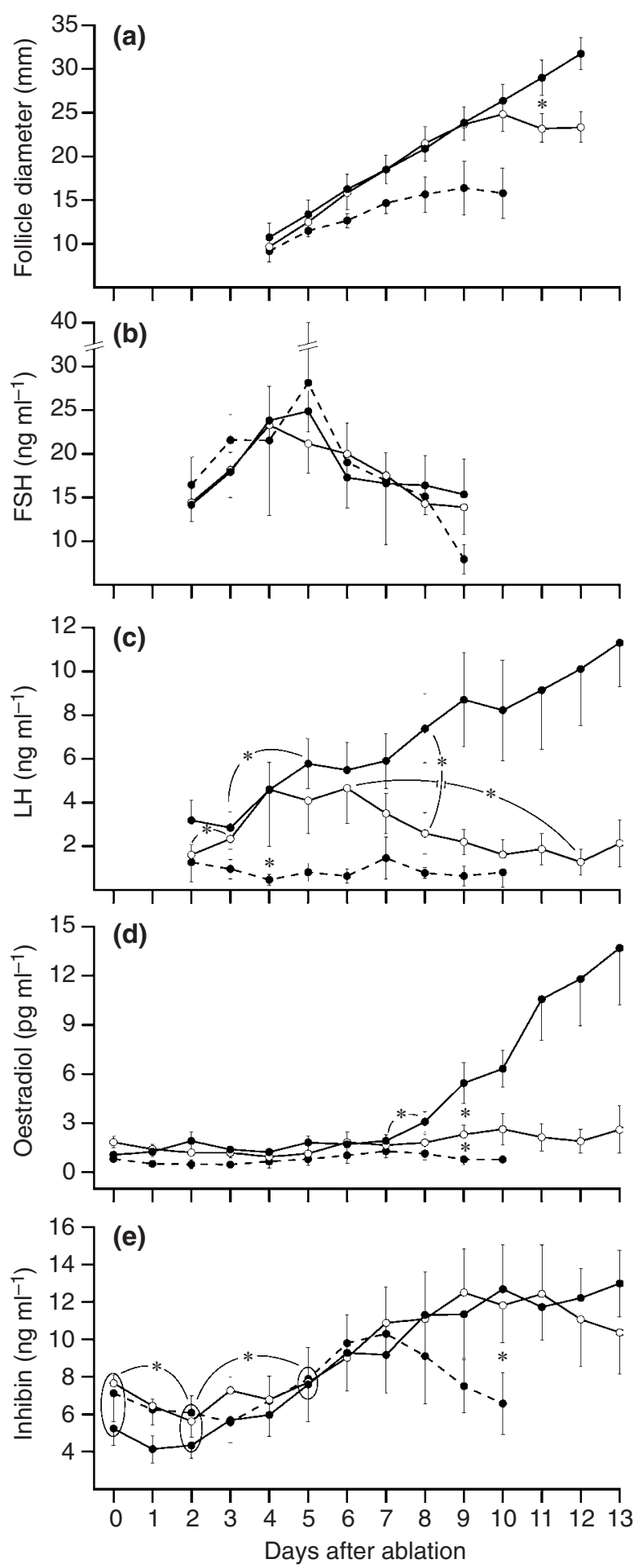

Fig. 2. Mean $\pm S E M$ for (a) diameter of largest follicle and concentrations of (b) FSH, (c) LH, (d) oestradiol and (e) total inhibin in mares in the ovulatory group (- - ), anovulatory-10 group $(-\bigcirc-)$ and anovulatory-60 (------) group. Follicles of $\geqslant 6 \mathrm{~mm}$ in diameter were ablated at day 10 after ovulation in the ovulatory and anovulatory-10 groups and at day 60 after ovulation in the anovulatory-60 group. Asterisks indicate a significant difference $(P<0.05)$ between the indicated groups within a day or between days within a group.

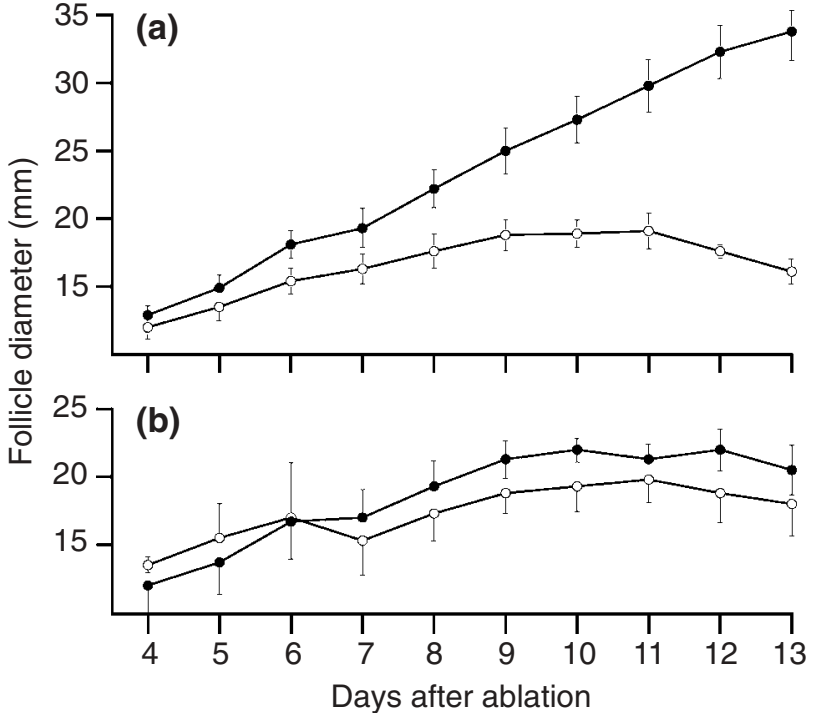

Fig. 3. Mean \pm SEM diameters for the two largest follicles for (a) ten mares in the ovulatory and anovulatory-10 groups with major waves and for (b) four mares in the anovulatory-10 group with minor follicular waves. ๑: Largest follicle; $\bigcirc$ : second largest follicle.

the waves $(P<0.08)$ approached significance. Eleven FSH surges (mean number per mare, 1.8) beginning and ending between day 10 and day 50 were identified in five of the six mares. The 11 surges were not significantly different from the post-ablation surge when centered on the FSH peaks (not shown). There was no significant change in follicle diameters when normalized to the peak of the 11 surges.

Both main effects and the interaction for oestradiol concentrations were significant $(P<0.02)$ for the three groups on days 0-10 after ablation and for the ovulatory and anovulatory groups on days $0-13$ (Fig. 2). The interaction was attributable to higher $(P<0.001$ to $P<0.02$ ) oestradiol concentrations in the ovulatory groups on each of days 9-13 than in the anovulatory10 group and higher oestradiol concentrations $(P<0.03)$ in the anovulatory- 10 group on day 9 and day 10 than in the anovulatory- 60 group. Concentrations of oestradiol in the ovulatory group first began to increase $(P<0.01)$ between day 7 and day 8 . Concentrations of oestradiol were higher in the mares with major waves $(P<0.05)$ on each of days 8,9 and 10 than those for mares with minor waves (Fig. 4). There were no differences between the four mares with a minor wave in the anovulatory-10 group and the mares in the anovulatory60 group (not shown). Oestradiol results normalized to observed deviation are shown (Fig. 5).

Changes in concentrations of total inhibin were significant for days averaged over the three groups for days 0 $10(P<0.002)$ and for the ovulatory and anovulatory-10 groups for days $0-13$ (Fig. 2; $P<0.0005$ ). Concentrations of total inhibin decreased $(P<0.01)$ between day 0 and 

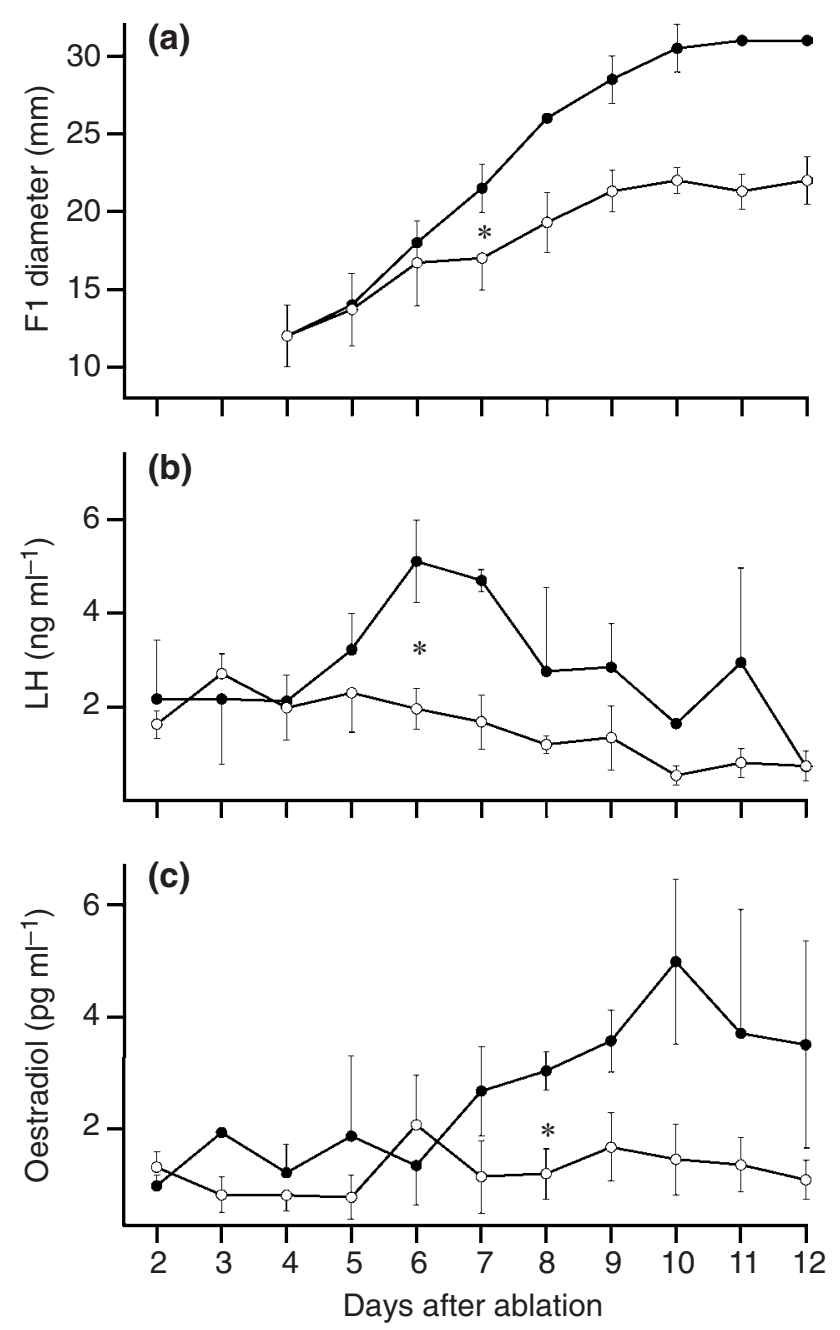

Fig. 4. Mean $\pm S E M$ for (a) diameter of largest follicle (F1) and concentrations of (b) $\mathrm{LH}$ and (c) oestradiol in mares in the anovulatory-10 group with major $(\bullet)$ and minor $(\bigcirc)$ follicular waves. Asterisks indicate the first day on which there was a significant difference $(P<0.05)$ between groups.

day 2 and started to increase $(P<0.05)$ between day 2 and day 5 . The concentrations of total inhibin for the ovulatory group and the anovulatory- 10 group appeared to increase up to day 8 or day 9 ; however, concentrations of total inhibin started to decrease in the anovulatory60 group beginning on day 7 , so that they were lower $(\mathrm{P}<0.05)$ than in the other two groups by day 9 . In the anovulatory mares, there were no significant differences in total inhibin concentrations between mares with major versus minor follicular waves or between the two groups of anovulatory mares with minor waves (not shown). Inhibin results normalized to deviation are shown (Fig. 5).

\section{Discussion}

A major follicular wave occurred in every mare in the ovulatory group and in two of six mares in the anovulatory-10 group during the 13 days after ablation,
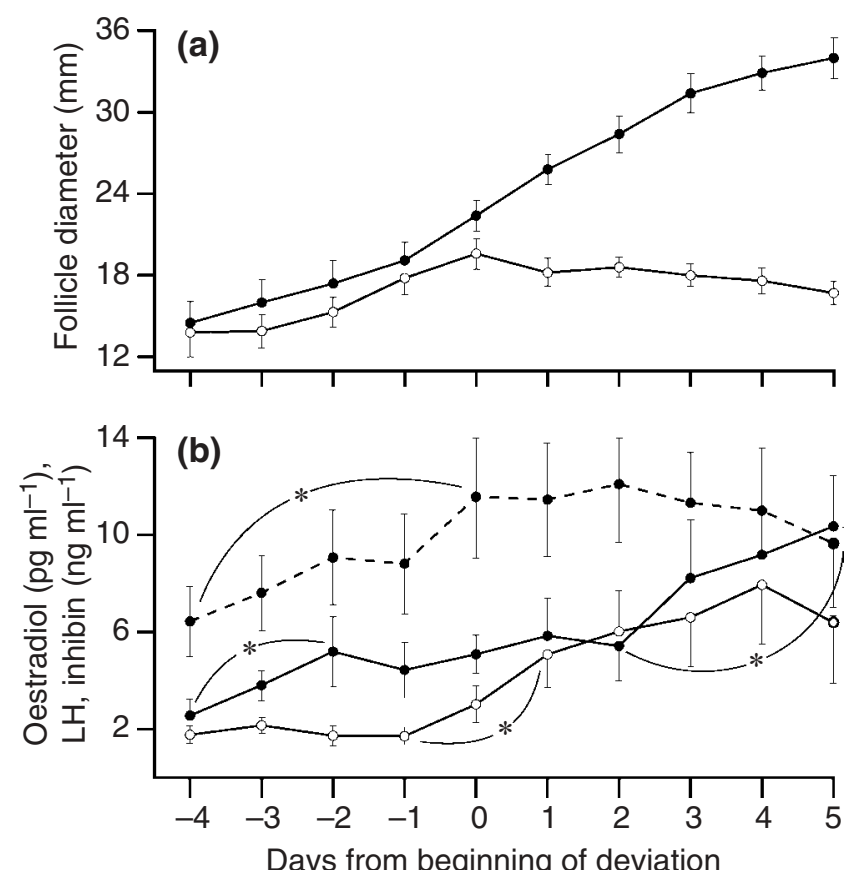

Fig. 5. Mean $\pm \mathrm{SEM}$ for (a) diameter of the two largest follicles ( largest follicle; $\bigcirc$ : second largest follicle) and (b) concentrations of total inhibin (------), LH (-๑) and oestradiol (- -() normalized to the beginning of observed deviation in follicle diameter in mares. Asterisks indicate a difference $(P<0.05)$ between days within a hormone.

but none occurred during the rest of the anovulatory period. The development of anovulatory follicles of dominant follicle size has been reported for the end of the anovulatory season (Watson et al., 2002), but this is apparently the first report of the emergence of major waves or cohorts of follicles followed by deviation in follicle diameter for any time during the anovulatory season. The mean day and diameter of F1 at the beginning of observed deviation for major waves during the ovulatory and anovulatory seasons and the mean changes in concentrations of circulating hormones when centered on the day of the beginning of observed deviation in follicle diameter were similar to reported findings during the ovulatory season (Gastal et al., 1997; Bergfelt et al., 2001; Donadeu and Ginther, 2001). The hormone changes that occurred were an oestradiol increase beginning the day before observed deviation, an inhibin increase that continued until the day of deviation followed by a plateau and an LH increase before deviation, a plateau encompassing deviation, and a subsequent increase as part of the ovulatory surge. Although only two major follicular waves were available during the anovulatory season, the $\mathrm{LH}$ and oestradiol increases near deviation were not sustained as in the ovulatory major follicular waves.

The growth of F1 was similar between the ovulatory and anovulatory- 10 groups for about 9 days after ablation of follicles, as indicated by the similar mean day-to-day 
diameters and by no difference in the number of days required for attainment of a $20 \mathrm{~mm}$ follicle. The reduction in diameter of $\mathrm{F} 1$ after day 9 in the anovulatory-10 group resulted in smaller follicle diameters at day 11 and day 12 and a reduced maximal diameter. Although these findings are more detailed, they are consistent with the report that the largest follicle was smaller at days 18-24 after the last ovulation of the year than at days 18-24 after the penultimate ovulation (Snyder et al., 1979). The failure of ovulation in mares that entered the anovulatory season was associated with reduced concentrations of $\mathrm{LH}$ encompassing the expected day of ovulation, as previously reported (Snyder et al., 1979; Irvine et al., 2000; Nequin et al., 2000), as well as a reduction in oestradiol. These findings are consistent with the concept that adequate circulating LH is needed for growth of the dominant follicle after deviation in follicle diameter in mares (Gastal et al., 1999a).

A positive feedback effect of oestradiol on circulating LH concentrations has been demonstrated in ovariectomized mares and in ovary intact mares after regression of the corpus luteum (for a review, see Ginther, 1992). However, results from ablation of the dominant follicle near the beginning of deviation in follicle diameter and thereby removal of the source of oestradiol resulted in an increase rather than a decrease in LH (Gastal et al., 1999b). In the present study, LH started to increase during the major follicular waves, whether ovulatory or anovulatory, several days before a detected increase in oestradiol. This initial increase in LH may have been a response to a decrease in progesterone (Gastal et al., 1997). On a temporal basis, the subsequent mean plateau concentrations of LH may have reflected a negative effect of oestradiol, based on the report that LH increases when the largest follicle is ablated at the expected beginning of deviation (Gastal et al., 1999b). The increase in LH after the plateau during the ovulatory major follicular waves but not during the anovulatory major follicular waves occurred as the oestradiol concentrations continued to increase. This part of the $\mathrm{LH}$ and oestradiol relationship is consistent with a positive feedback effect of oestradiol. The intricacies of the apparent changes in the reciprocal relationships between oestradiol and $\mathrm{LH}$ will require further study.

In addition to the minor follicular waves during the 10 days after ablation in four mares in the anovulatory10 group and in all six mares in the anovulatory- 60 group, minor follicular waves were detected between day 10 and day 50 after ablation in five of six mares. Minor waves have been reported during the later part of the anovulatory season (Donadeu and Ginther, 2002), but this is the first report of their occurrence during the first 2 months. The anovulatory months of the present study (approximately December and January) and the previous study (February to April) together encompassed the entire anovulatory season in ponies. In the present study, as in the previous study, some minor follicular waves likely were obscured by the masking effect of regressing follicles from a previous wave, as described by Donadeu and Ginther (2002).

The FSH surge after ablation started at a similar time and had a similar profile among the three groups, despite the differences in follicle development. In addition, the FSH surge that followed ablation in the anovulatory-10 group was similar to surges identified during days $10-50$. The FSH surges detected during early dioestrus and in the anovulatory mares during days 10-50 after ablation (excludes the surges after ablation) were based on conservative criteria. Nevertheless, an increase in follicle diameters was not detected in association with these surges. Similarly, a significant increase and decrease in FSH concentrations were not detected in association with the five identified minor follicular waves during days 10 50 , although the changes in $\mathrm{FSH}$ concentrations did approach significance. It is concluded that FSH surges with similar patterns occur during early dioestrus and throughout the anovulatory season. Detectable follicular waves frequently do not occur in association with these surges, and waves that do occur may differ profoundly in the extent of follicle development. During both ovulatory and anovulatory seasons, approximately $0.5 \mathrm{FSH}$ pulses occur per day, as determined by sampling at 4 or $6 \mathrm{~h}$ intervals (Irvine et al., 1998, 2000). These pulses presumably are superimposed on the FSH surges as defined from samples obtained daily in the present and previous studies (Bergfelt and Ginther, 1993; Donadeu and Ginther, 2002, 2003). The irregularities in the surges can be attributed, at least in part, to daily sampling at various times during a pulse.

The findings of minor waves and consistency in the profiles of FSH surges for the first 2 months of the anovulatory season are in agreement with a conclusion (Donadeu and Ginther, 2002, 2003) that differences in the extent of follicle development for minor waves occurring during the later part of the anovulatory season were not attributable to changes in the characteristics of the associated FSH surge. Temporal differences in circulating LH did not account for the greater follicle activity in some minor follicular waves than in others (Donadeu and Ginther, 2002, 2003). In the present study, there were temporal indications that differences in $\mathrm{LH}$ concentrations may have been involved. The mares with minor waves after ablation in the anovulatory- 10 group had both larger follicles and greater associated LH concentrations than the mares with minor waves in the anovulatory- 60 group. These findings indicate on a temporal basis that higher $\mathrm{LH}$ concentrations may account for differences in follicle activity of minor waves. Further study is needed on the changes in follicle responsiveness to $\mathrm{FSH}, \mathrm{FSH}$ receptor expression, half-life of FSH isoforms, and frequency and amplitude of LH pulses (Donadeu and Ginther, 2002).

The largest mean diameter of F1 in mares with minor waves $(22.8 \mathrm{~mm})$ in the anovulatory-10 group was similar 
to the mean diameter of $\mathrm{F} 1$ at the beginning of deviation in the major follicular waves $(22.4 \mathrm{~mm})$ in the ovulatory and anovulatory-10 groups. Thereafter, F1 and F2 did not continue to grow in the minor waves so that the diameter profile of $\mathrm{F} 1$ was not significantly different from the profile of F2 in the major waves. That is, F1 in minor waves reached a diameter characteristic of deviation in follicle diameter but thereafter did not continue to grow. In addition, LH concentrations encompassing the beginning of deviation in follicle diameter were greater in the major waves than during the corresponding time in the minor waves. These results provide support for the concept that the future dominant follicle of mares requires an additional LH stimulus at the beginning of deviation in follicle diameter (for a review, see Ginther et al., 2001) and also indicates that $\mathrm{LH}$ provides, in effect, the stimulus for the conversion of a minor to a major follicular wave.

In conclusion, the hypotheses that both major and minor follicular waves develop during the early portion of the anovulatory season and that both types of waves are temporally associated with an FSH surge were supported. Characteristics of the wave-stimulating FSH surges were similar, despite differences in the resulting follicle activity. Minor follicular waves were detected throughout the initial 2 months of the anovulatory season. Both diameter of $\mathrm{F} 1$ and concentrations of $\mathrm{LH}$ for minor follicular waves were greater after ablation at day 10 after the last ovulation of the year than after ablation at day 60 . These results indicate that $\mathrm{LH}$ accounted for the differences in follicle growth among minor follicular waves, despite the similarities in the FSH surge. Deviation in follicle diameter occurred during major waves at the beginning of the anovulatory season as well as during the ovulatory season. Mean growth of F1 of minor waves after follicle ablation at day 10 after the last ovulation of the year was similar to growth of $\mathrm{F} 1$ of major waves after ablation during an interovulatory interval but only until F1 reached a mean diameter characteristic of the beginning of deviation. Concentration of $\mathrm{LH}$ was greater for major than for minor follicular waves, indicating on a temporal basis that a minor wave developed into a major wave when $\mathrm{F} 1$ reached a diameter characteristic of the beginning of deviation in follicle diameter in the presence of an adequate $\mathrm{LH}$ stimulus for continued growth of a dominant follicle.

This study was supported by the Eutheria Foundation, Project P3-OG-01. The authors thank S. Jensen for technical assistance and A. F. Parlow from the National Hormone and Pituitary Program for gonadotrophin radioimmunoassay reagents and the Pharmacia Company for a gift of Lutalyse.

\section{References}

Bergfelt DR and Ginther OJ (1992) Relationships between circulating concentrations of $\mathrm{FSH}$ and follicular waves during early pregnancy in mares Equine Veterinary Science 12 274-279
Bergfelt DR and Ginther OJ (1993) Relationships between FSH surges and follicular waves during the estrous cycle in mares Theriogenology 39 781-796

Bergfelt DR, Gastal EL and Ginther OJ (2001) Response of estradiol and inhibin to experimentally reduced luteinizing hormone during follicle deviation in mares Biology of Reproduction 65 426-432

Donadeu FX and Ginther OJ (2001) Effect of number and diameter of follicles on plasma concentrations of inhibin and FSH in mares Biology of Reproduction 121 897-903

Donadeu FX and Ginther OJ (2002) Follicular waves and circulating concentrations of gonadotrophins, inhibin and oestradiol during the anovulatory season in mares Reproduction 124 875-885

Donadeu FX and Ginther OJ (2003) Interactions of follicular factors and season in the regulation of circulating concentrations of gonadotropins in mares Reproduction 125 743-750

Fitzgerald BP, L'anson H, Legan SJ and Loy RG (1985) Changes in patterns of luteinizing hormone secretion before and after the first ovulation in the postpartum mare Biology of Reproduction 33 316-323

Gastal EL, Gastal MO, Bergfelt DR and Ginther OJ (1997) Role of diameter differences among follicles in selection of a future dominant follicle in mares Biology of Reproduction 57 1320-1327

Gastal EL, Bergfelt DR, Nogueira GP, Gastal MO and Ginther OJ (1999a) Role of luteinizing hormone in follicle deviation based on manipulating progesterone concentrations in mares Biology of Reproduction 611492 1498

Gastal EL, Gastal MO and Ginther OJ (1999b) Experimental assumption of dominance by a smaller follicle and associated hormonal changes in mares Biology of Reproduction 61 724-730

Ginther OJ (1992) Reproductive Biology of the Mare, Basic and Applied Aspects 2nd Edn Equiservices Publishing, Cross Plains, WI

Ginther OJ (1993) Major and minor follicular waves during the equine estrous cycle Journal of Equine Veterinary Science 13 18-25

Ginther OJ (1995) Ultrasonic Imaging and Animal Reproduction: Book 2, Horses Equiservices Publishing, Cross Plains, WI

Ginther OJ and Bergfelt DR (1992) Associations between FSH concentrations and major and minor follicular waves in pregnant mares Theriogenology 38 807-821

Ginther OJ, Beg MA, Bergfelt DR, Donadeu FX and Kot K (2001) Follicle selection in monovular species Biology of Reproduction $\mathbf{6 5}$ 638-647

Irvine CH, Turner JE, Alexander SL, Shand N and van Noordt S (1998) Gonadotrophin profiles and dioestrous pulsatile release patterns in mares as determined by collection of jugular blood at $4 \mathrm{~h}$ intervals throughout an oestrous cycle Journal of Reproduction and Fertility 113 315-322

Irvine CHG, Alexander SL and McKinnon AO (2000) Reproductive hormone profiles in mares during the autumn transition as determined by collection of jugular blood at $6 \mathrm{~h}$ intervals throughout ovulatory and anovulatory cycles Journal of Reproduction and Fertility 118 101-109

Nequin LG, King SS, Roser JF, Soderstrom BL, Carnevale EM and Neumann KR (2000) Uncoupling of the equine reproductive axes during transition into anoestrus Journal of Reproduction and Fertility Supplement 56 153161

SAS Institute Inc. (1995) Introduction to the MIXED Procedure SAS Institute, Inc., Cary, NC

Snyder DA, Turner DD, Miller KF, Garcia MC and Ginther OJ (1979) Follicular and gonadotrophic changes during transition from ovulatory to anovulatory seasons Journal of Reproduction and Fertility Supplement 27 95-101

Roser JF, McCue PM and Hoye E (1994) Inhibin activity in the mare and stallion Domestic Animal Endocrinology 11 87-100

Watson ED, Heald M, Tsigos A, Leask R, Steele M, Groome NP and Riley SC (2002) Plasma FSH, inhibin A and inhibin isoforms containing pro- and $\mathrm{dC}$ during winter anoestrus, spring transition and the breeding season in mares Reproduction 123 535-542

Received 6 May 2003.

First decision 30 June 2003.

Revised manuscript received 4 July 2003.

Accepted 18 July 2003. 